\title{
Richard Payne. A State of Mixture: Christians, Zoroastrians, and Iranian Political Culture in Late Antiquity
}

Christelle Jullien

\section{(2) OpenEdition \\ 1 Journals}

Édition électronique

URL : http://journals.openedition.org/abstractairanica/43459

DOI : $10.4000 /$ abstractairanica. 43459

ISBN : 1961-960X

ISSN : 1961-960X

Éditeur :

CNRS (UMR 7528 Mondes iraniens et indiens), Éditions de l'IFRI

\section{Référence électronique}

Christelle Jullien, «Richard Payne. A State of Mixture: Christians, Zoroastrians, and Iranian Political Culture in Late Antiquity ", Abstracta Iranica [En ligne], Volume 37-38-39 | 2018, document 5, mis en ligne le 30 décembre 2018, consulté le 29 septembre 2020. URL : http://journals.openedition.org/ abstractairanica/43459; DOI : https://doi.org/10.4000/abstractairanica.43459

Ce document a été généré automatiquement le 29 septembre 2020.

Tous droits réservés 


\title{
Richard Payne. A State of Mixture: Christians, Zoroastrians, and Iranian Political Culture in Late Antiquity
}

\author{
Christelle Jullien
}

\section{RÉFÉRENCE}

Richard Payne. A State of Mixture: Christians, Zoroastrians, and Iranian Political Culture in Late Antiquity. Oakland: University of California Press, 2015, 320 p., (Transformation of the Classical Heritage 56), ISBN 978-0520286191.

1 Ce livre est l'aboutissement d'une thèse de doctorat soutenue en 2010 sur le christianisme et la société iranienne dans l'Antiquité tardive entre les années 500 et 700. Il s'agit d'une importante contribution à l'histoire des sociétés dans l'empire sassanide, appréhendée sous l'angle des relations inter-religieuses entre communautés chrétiennes et mazdéennes à l'époque préislamique. L'ouvrage écarte l'idée d'une marginalisation des minorités en particulier chrétiennes sous les Sassanides, réinsistant avec raison sur l'ampleur de l'acculturation de l'aristocratie chrétienne en Iran et leur insertion dans les institutions, et plus largement les réseaux sociopolitiques d'un empire qu'ils contribuèrent aussi à développer. Il faut ainsi saluer l'effort accompli, à l'appui d'une riche documentation aussi bien littéraire qu'archéologique, pour illustrer ce phénomène, spécialement l'adoption de pratiques et de coutumes comme aussi de modes de pensée propres à une autre culture, celle des élites perses. L'A. est un historien philologue qui part des concepts des sciences sociales pour déceler à travers les sources antiques et médiévales certains mécanismes parfois inexplorés. À la base, l'A. défend l'idée d'un pacte tacite entre les autorités sassanides et la hiérarchie de l'Église syro-orientale régulant les actions missionnaires et le développement des communautés, en échange d'une reconnaissance sociale par la participation à la culture politique d'un empire fondamentalement mazdéen. Au sein de cette culture iranienne, les chrétiens se sont aussi positionnés pour façonner leurs 
propres histoires, notamment celles de modèles hagiographiques, et pour créer des conditions compatibles avec leurs valeurs (en particulier sur le plan moral et juridictionnel). L'idée d'un pacte tacite se fonde sur les travaux de H. Drake et de Peter Brown qui ont développé des recherches sur l'implication du politique dans la création des conditions d'un équilibre intercommunautaire dans le cadre de l'empire romain oriental à l'époque constantinienne (IVe s.). L'A. reprend ici ce concept mais transposé à l'empire iranien et d'autre part étendu à toute la période sassanide (IVe-VIIe s.), ce qui invite à apporter des nuances à ces positions. On notera d'autre part, sous-jacent à ce travail, l'importante influence de réflexions comme celles de A. V. Williams (en particulier "Zoroastrians and Christians in Sasanian Iran ", Bulletin of the John Rylands University Library of Manchester 78/3, 1996, p. 37-53).

2 Au cœur de cette étude, l'A. réévalue finalement les rapports des chrétiens avec le pouvoir en proposant, par une vigoureuse critique des sources hagiographiques, de remettre en question la réalité de persécutions de la part des autorités perses zoroastriennes, évoquant ainsi un « Myth of Intolerance » des sources syriaques - une expression qui fait sans doute écho aux «Limits of Intolerance » de Peter Brown. Il est à relever que ce point de vue est aussi celui actuellement proposé par toute une école de jeunes chercheurs américains : voir récemment $K$. Smith sur la période de šābuhr II par exemple, The Martyrdom and History of Blessed Simeon bar Sabba'e (2014), ou P. Wood pour l'Histoire syro-orientale de Séert (2013). The state of mixture appartient au courant 'révisionniste' évoqué par B. Caseau-Chevallier dans une analyse récente (« ПO $\mathrm{EMEIN}$ $\Lambda \mathrm{I} \Theta O I \Sigma$. La désacralisation des espaces et des objets religieux païens durant l'Antiquité tardive ", dans M. Kaplan (éd.), Le sacré et son inscription dans l'espace à Byzance et en Occident: Études comparées, (Publications de la Sorbonne. Série Byzantina Sorbonensia 18), Paris, 2001, p. 61-124, ici p. 67), qui consiste à prendre ses distances vis-à-vis d'une littérature engagée dans une rhétorique de la victoire du christianisme dans les milieux "païens", et qui considère les développements narratifs sur la violence religieuse comme un parti-pris des auteurs des sources. Les études de M. P. Penn ont bien mis en évidence les expressions littéraires de ce qu'il appelle une rhétorique "inversée". Il convient néanmoins d'adopter et de trouver le juste équilibre dans la lecture des sources sans tomber non plus dans l'excès inverse et, tout en en évaluant la nature, le genre et la teneur, de ne pas tout rejeter sous prétexte de rédactions délibérément orientées. Il y a certes une option de lecture des hagiographes et historiographes sur la question des "persécutions", mais elle ne cache pas complètement une réalité douloureuse. Voir en particulier dernièrement pour le VIe siècle P. C. Dilley dans son introduction (S. P. Brock, P. C. Dilley, The Martyrs of Mount Ber'ain, (Persian Martyr Acts in Syriac: Text and Translation 4), Piscataway, 2014). Les communautés chrétiennes vivant dans l'empire iranien à l'époque tardo-antique, de l'Arabie à l'Afghanistan, se sont développées sur des territoires culturellement et géographiquement disparates, au sein des réseaux et des institutions étatiques auxquels elles ont pris part. Ce livre apporte une pierre supplémentaire notable à la perception d'un empire que caractérise bien une société plurielle dans la richesse de ses cultures. Une présentation préliminaire des principales orientations de l'ouvrage avait été faite par l'A. notamment en 2014 dans News and Notes, une revue généraliste de l'Oriental Institute d'Oxford (« The Rise of Christianity in Iran", News and Notes 223, 2014, p. 2-7; notes et références bibliographiques p. 33). 


\section{AUTEURS}

\section{CHRISTELLE JULLIEN}

CNRS, Mondes iranien et indien, Paris 